\title{
Indigenous Fishing Methods of the Moyon Tribe of Manipur (India) and Myanmar
}

\author{
Wanglar Alphonsa Moyon ${ }^{1 *} \&$ Elija Chara ${ }^{2}$ \\ Department of Zoology, South East Manipur College, Komlathabi, Manipur, India \\ Department of Sociology, Highland National College, Kanglatongbi, Manipur, India \\ Correspondence Email: alphonshawanglar@gmail.com \\ https://riiopenjournals.com/index.php/society sustainability/index
}

Doi:https:https//doi.org/10.38157/society_sustainability.v3i2.334

Citation:Moyon, W. A. \& Chara, E.(2021). Indigenous Fishing Methods of the Moyon Tribe of Manipur (India) and Myanmar,Society\&Sustainability, 3(2), 54-67. Doi: https://doi.org/10.38157/society_sustainability.v3i2.334

\section{Research Article}

\begin{abstract}
Fishing is one of the main economic activities of the Moyon tribe living in Manipur (India), and Myanmar. For many centuries, Moyons used indigenous methods for fishing. However, in recent years, indiscriminate fishing using modern technologies has led to an ecological crisis which not only affected the ichthyofauna diversity but also affected the livelihood of individuals depending on fishing as well as the sustainability of the indigenous fishing methods. The paper explores the indigenous fishing techniques and practices of the Moyon tribe. The study adopted a qualitative-exploratory research method with ethnography as the primary component. Data were collected from on-site observations of fishing and discussions with the local Moyon population. The study revealed that indigenous fishing methods have become unsustainable due to misuse by the fishers. Another significant observation was the shift in fishing methods from traditional to modern (market) gears. The recently used fishing gears are a threat to the fish population, aquatic ecosystem, and indigenous knowledge of fishing crafts. The study concludes that unsustainable fishing by the Moyon tribe is connected with poverty and the lack of development and education.
\end{abstract}

Keywords:Moyon tribe, Indigenous, Fishing methods, India, Myanmar

\section{Introduction}

The Moyon tribe inhabits the Chakpi, Maha, and Lokchao sub-basins of the larger Chindwin River Basin in Manipur (India) and Myanmar. They make good use of these rivers by extensively fishing them since time immemorial (Wanglar et al, 2018). Fishing is one of the many traditional occupations seasonally supporting many families. Fishing is not only the source of livelihood for the people, it supplements their diets and is also an integral part of the cultural heritage. For centuries, the Moyons used simple indigenous methods to fish, and the catch was enough to supplement the people's needs. They also used indigenous fish preservation techniques to preserve the catch (Wanglar et al, 2018). However, the ever-increasing population 
coupled with an increased appetite for fish resulted in abuses of indigenous methods and the introduction of modern fishing techniques and thus slowly threatening the future of the fishing and fish population. The erstwhile pristine hill streams rich in fish population and diversity are now slowly devoid of fishes which is a great concern not only for the fishers and fishes but also for scientists and environmentalists as well.

The Chandel and Tengnoupal districts of Manipur are inhabited by numerous tribes and subtribes; some of the tribes are- Anal, Aimol, Monsang, Moyon, Lamkang, Tarao, Maring, Zou, and Thadou. These tribes employed various traditional fishing methods for fishing. Each tribe is unique in its fishing techniques and methods. Despite the widespread usage of traditional fishing methods, there has been no research on this area. The closest available study is on the indigenous fish preservation methods by the Moyon tribe (Wanglar et al, 2018) which highlighted the various traditional methods employed to preserve fish and the associated social knowledge on these traditional preservation methods. In addition, ichthyofauna studies in Chandel District (leading to discoveries of new fish species) on large exclude descriptions of the fish collection methods (if the fishes were caught using traditional methods or modern methods); thus, it can be said that the region's indigenous knowledge largely remains unexplored and undocumented. This article aims to initiate venturing into this unexplored premise to bring into the picture the uniqueness of indigenous knowledge and skills of the region from the perspectives of social and environmental sustainability. Accordingly, the article focuses on two objectives:

i. To discuss the indigenous methods of fishing of the Moyons

ii. To comprehend the need for a balanced and sustainable fishing awareness.

\section{Materials and Methods}

The paper is subjectively concentrated on the Moyon community's fishing methods following a descriptive-qualitative research pathway and ethnographic studies. Information on fishing methods was obtained from an on-site study. The main duration of the study was from 2017 to 2019. The study also involved observations of fishing and anecdotes from interviews with local folks.

The on-site study of the community fishing known as Chiituk was done at Chiikuk River, a tributary of the Chakpi River. The researchers participated in the community fishing. Information on ichthyotoxic plants used for fishing was obtained, along with the usage of some fishing gears and their applications. The traditional fishing gears and their applications were also noted from on-site studies, including fishing trips, from 2017 to 2019, at the Chakpi, Maha, and Lokchao rivers. The long duration of the study was necessary as different fishing methods were used during different parts of the year. The on-site study strengthened the information shared by the community, as it involved actual demonstration and application of those fishing gears.

In addition, interviews and discussions were also held with the villagers. Another aspect that played a major role was field observation, which was useful in analyzing the modus of those methods and assessing the viability/sustainability of the fishing methods used. 


\section{Brief Profile of the Moyon tribe}

The Moyon is a small tribe inhabiting the Chandel and Tengnoupal districts of Manipur in India and the Sagaing Region of Myanmar. Their total population is about 2,600 and is distributed in 18 villages (Chara 2018, 2021). The name Moyon or Moyon Naga is an exonym, but the people prefer to be called 'Bujuur' for social, cultural, historical, emotional, and political reasons [Chara, 2018). The tribe as well and the region inhabited by them remain one of the least research spaces to date.

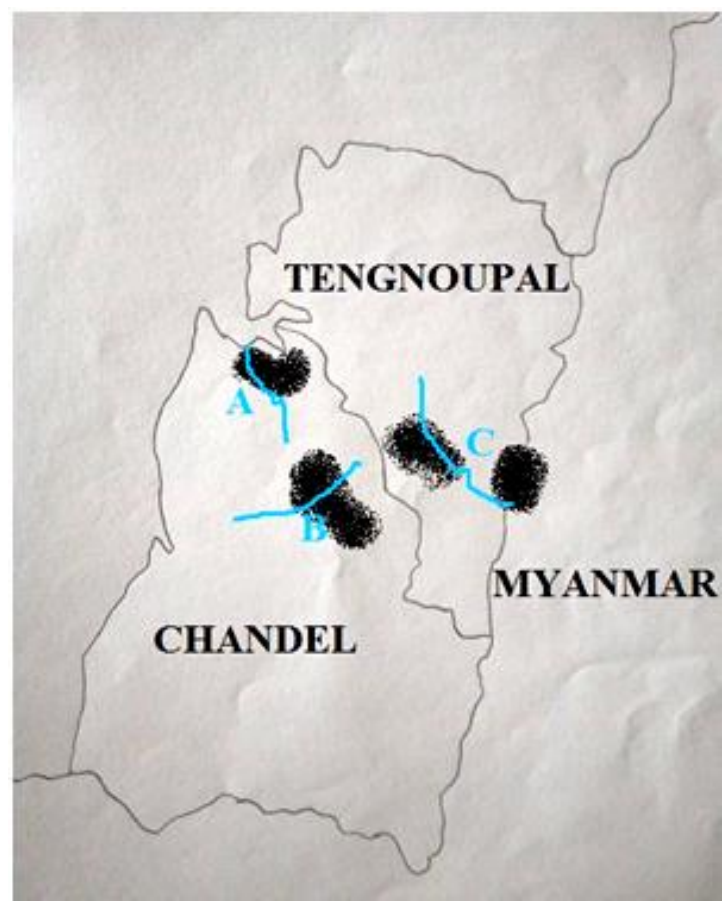

Figure 1. Areas inhabited by the Moyons in black shades, along with river basins of Maha (A), Chakpi (B), and Lokchao (C)

\section{Results}

\subsection{Indigenous fishing Methods}

The Moyons were known for their various ingenious indigenous fishing techniques which they have been using since time immemorial (Wanglar, 2018). Understanding these local fishing techniques is vital to ascertain the state of sustainability. Different techniques of fishing were employed depending on the seasons and they can be categorized as (i) Herbal fishing, (ii) Barrier fishing, (iii) Simple manual, and (iv) River modification. These techniques of fishing categories are briefly described below.

\subsubsection{Herbal fishing}

This category of fishing technique makes use of ichthyotoxic plants (see table 1 for a few examples). It is also known as chiituk. Chiituk can be either a community event or private.

a. Community fishing (Chiituk): Community fishing or Chiituk usually takes place during the spring season when the water levels are at the lowest. On the day of Chiituk, the entire community with fishing gears go to a selected site of the river. Ichthyotoxic plants are the main 
components of chiituk. These ichthyotoxic plants are collected and soaked in the river a day before the main fishing event. On the fishing day, the men smash the ichthyotoxic plants' roots, leaves, stems, barks, or fruits (depending on the plant species and utility) into pulp till the water (or portion of the river) are covered in foam (Fig.1). The toxic from the plants stun the fishes which would then be collected by the people (Fig.2). Some of the ichthyotoxic plants used for Chiituk include Langthrii, Naga runoh, Kekemar, Iriih, Ruphoh, Jaerii, and Taepuung (see Table 1 for more details). It may be noted that the effects of the ichthyotoxins depend on the quantity of the materials used (Wanglar and Arunkumar, 2017). The effect of the toxins may extend to about 3$4 \mathrm{~km}$ downstream.

Chiituk is reserved for large-scale fishing only involving the community. However, it is traditionally considered destructive as it not only affects the fishes but also causes large-scale havoc on aquatic life. Thus, despite its community importance and promises of a good catch, Chiituk was rarely practiced even in the past and several years of gaps were traditionally mandated between chiituk.

\section{Table 1: Some Ichthyotoxic Plants Used for Fishing}

\begin{tabular}{|l|l|l|l|l|}
\hline $\begin{array}{l}\text { S1. } \\
\text { No. }\end{array}$ & $\begin{array}{l}\text { Local Name } \\
\text { (Moyon) }\end{array}$ & Scientific Name & Family & Parts used \\
\hline 1 & Ruphoh & Albizia chinensis (Osbeck) Merr. & Fabaceae & whole \\
\hline 2 & Jaerii & Milletia pachycarpa Benth. & Papilionaceae & roots and seeds \\
\hline 3 & Lampahaepi & Catunaregam spinosa (Thunb.) & Rubiceae & fruits \\
\hline 4 & Mangkha & Juglans sp. & Juglandaceae & $\begin{array}{l}\text { barks, leaves, and } \\
\text { rind of unripe } \\
\text { fruit }\end{array}$ \\
\hline 5 & Taepuung & Acacia pruinescens Kurz. & Fabaceae & whole \\
\hline 6 & Langthrii & Blumea balsamifera (Linn.) DC. & Asteraceae & leaves \\
\hline 7 & Naga runoh & $\begin{array}{l}\text { Mikania cordata (Burm.f.) B.L. } \\
\text { Robinson }\end{array}$ & Asteraceae & $\begin{array}{l}\text { stem, roots, and } \\
\text { leaves }\end{array}$ \\
\hline 8 & Ivatishikbashiirrii & Costus speciosus (J. Koenig) Sm. & Costaceae & whole plant \\
\hline 9 & Iriih & $\begin{array}{l}\text { Gnetum montanum Markgraf } \\
\text { stem, roots, bark, } \\
\text { and leaves }\end{array}$ \\
\hline 10 & Shinii & Zanthoxylum armatum DC. & Rutaceae & bark \\
\hline 11 & Kwanruwchaang & Smilax lanceifolia Roxb & Smilacaceae & whole plant \\
\hline
\end{tabular}

Source: Wanglar and Arunkumar, 2017; Wanglar, 2018, p.145

b. Chiituk (private/individual/group): The fishing procedure is almost similar to community fishing, except it involves less number of people. Whereas community chiituk fishing is more like a ritual and community event taking place once in a few years, this private party chiituk fishing can take place every year. It is less regulated and has no symbolic meaning for the community. As it is private fishing, this is sometimes abused especially if the fishing party uses large quantities of an ichthyotoxic plant by the name Jaerii (Milletia pachycarpa). Since Jaerii is considered a very potent ichthyotoxic plant, its unregulated usage often resulted in aquatic disasters. Using Jaerii to fish is known as Jaerii ibob. 


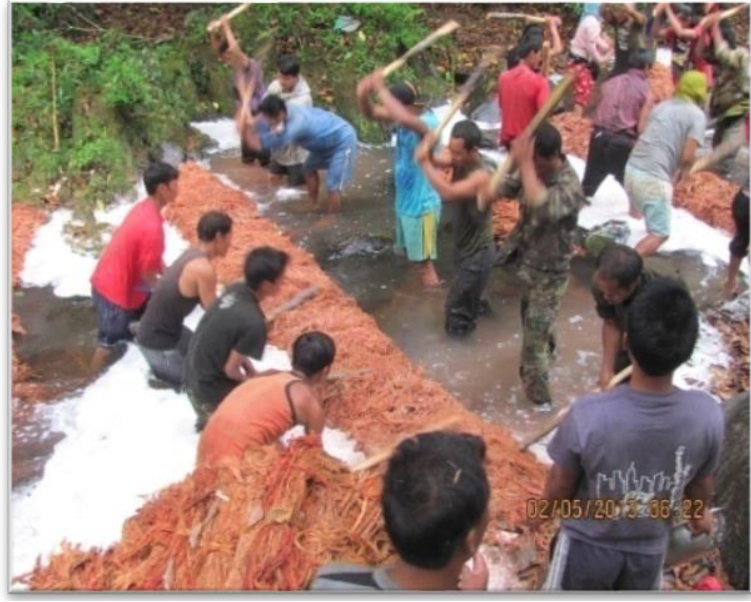

Fig.2.Smashing of Albizia chinensis

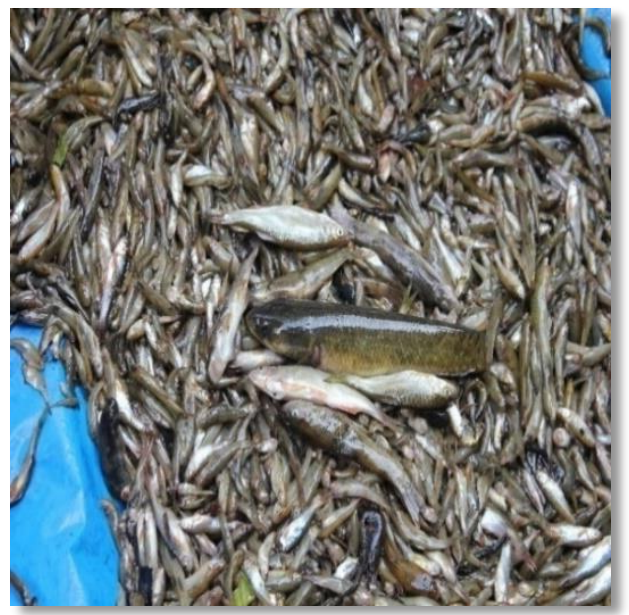

Fig.3. Fishes caught during Chiituk During Chiituk

\subsubsection{Barrier Fishing}

This fishing method involves the employment of barriers. Some important techniques under this category are described as follows.

a. Chapen Iting (Fig.4): Chapen is a barrier guide erected in the river and the method is called Chapen Iting The barrier is made of stones, woods, twigs, and leaves. A small gap is opened in the middle of the barrier where a conical trap is placed. Fishes would enter the conical trap following the streamflow. This technique is used mainly in rivers and streams with a considerable flow of water.

b. Iruw : Iruw is a bamboo conical trap (Fig 5). It is used as a part of the chapen iting. However, conical traps as a standalone technique are widely used to catch fishes in small ephemeral streams and channels when water and fishes are available.

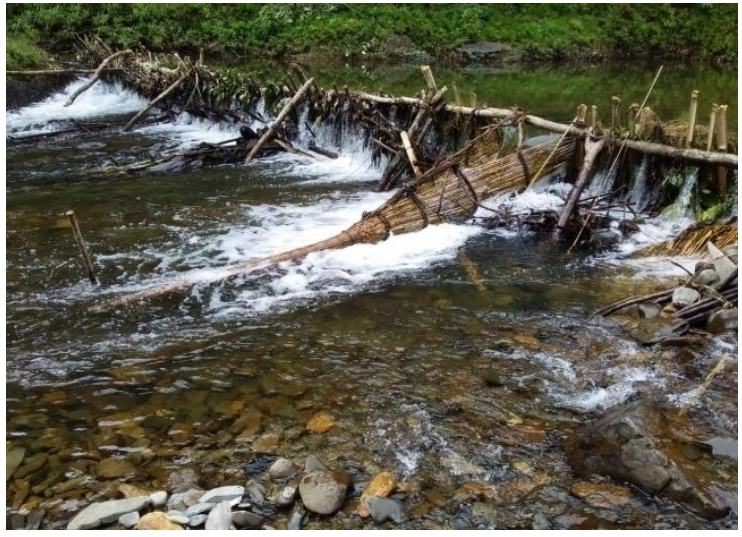

Fig. 4: Chapen (barrier guide)

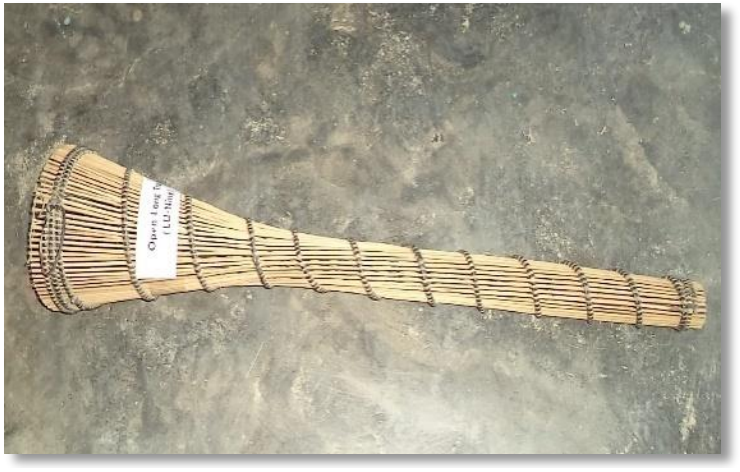

Fig. 5:Iruw (conical trap)

\subsubsection{Manual fishing}

This fishing category is by far the most employed technique regardless of season and water level. Some of the techniques include:

a. Kik ing isuwr (Fig.6): As the name indicated, this method involves fishing using bare hands. Target fishes are caught by hands. In the past when fishes were plentiful, people would often 
catch fish with their bare hands. The success rate is low; nevertheless, it was considered a great skill and an adventure requiring patience and sharp eyesight.

b. Chem: This simple method employs chem (machete). This method is specially used at night with the help of lights such as marra (pine flame-torch), torchlight, lantern, etc. Fishes in shallow or marginal portions of the river get attracted to the light as well as get momentarily blinded. Taking advantage of the fishes' immobility, chem is used to hit-cut the fish.

c. Isii (spear): A single iron pointed spear or detachable fork of three barbed points is fastened to a bamboo rod or wooden shaft by a fine string. The spear is thrown at the target fish. This technique requires patience, skill, and attention. A single-pointed spear is preferred for spearing large fish whereas forked spears are used for spearing small to medium size fishes.

d. Lungtuk (hammering): Boulders and rocks serve as a hiding place for fishes. When such selected rocks/bounders are struck with a strong blow using a hammer or baton (known as haebob), it generates a vibration and shock waves forcing the fishes to surface or move to open/shallow areas where they are caught.

e. Bows and arrows/TharRuwpher (Fig. 7): This method is used for shooting fishes like catfish and carps. The bowstring is made up of fine bamboo or cane strips. A single-pointed prong or multiple pointed prongs is attached to the tip of the arrow. Target fishes are shot at. This technique requires skill and patience.

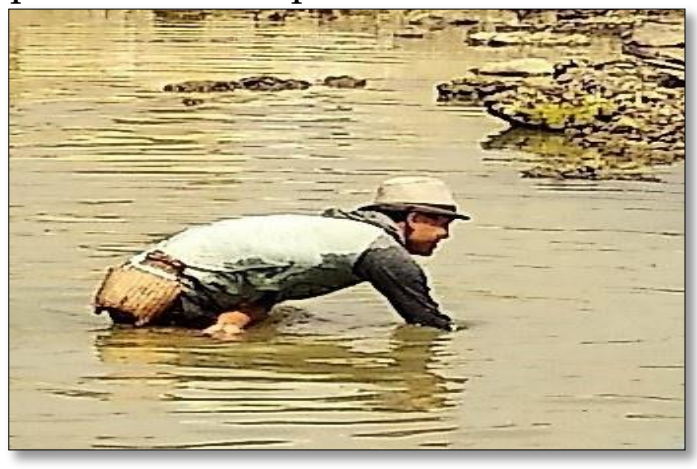

Fig. 6: Kikingisuwr (gropping)

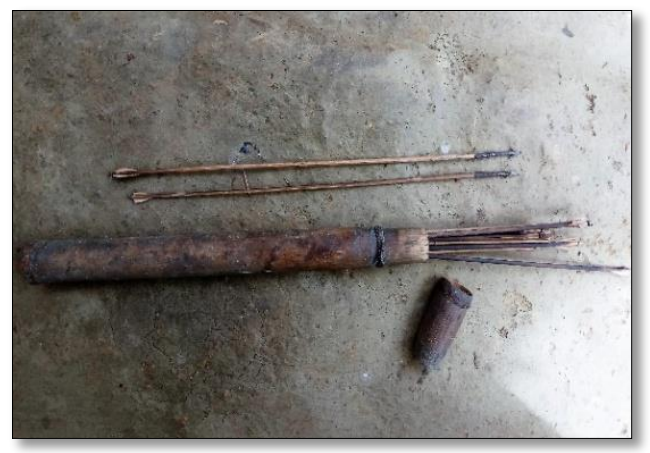

Fig.7:TharRuwpher

f. Ngakaapniithar (fishing bow): This is a fishing gear in which multiple pointed iron prongs are fastened at the end of a meter-long bamboo rod. At the other end, a light-weighted iron pipe is inserted inside the rod and two sling rubbers are fastened to the base of the rod (Fig.8). Catching hold of the iron pipe, the sling is pulled backward and let off to push the rod forward to hit the target fish. It is best used at night in clear streams.

g. Long and Bukaangidii (scoop basket) (Fig. 9): Long and Bukaangidii are are an oval-shaped bamboo baskets with a rounded mouth. The rim is wide opened and supported by a cane to which traps are woven. This method is popular among the womenfolk during the dry season when the water levels are low. It is mainly employed for catching fishes hiding under leaves, debris, pebbles, and mud. Using their hands, the materials are scooped towards the basket. These fishing gears are mostly used for catching smaller-sized fishes and aquatic insects. It is very popular at the Maha River and is used throughout the year. 

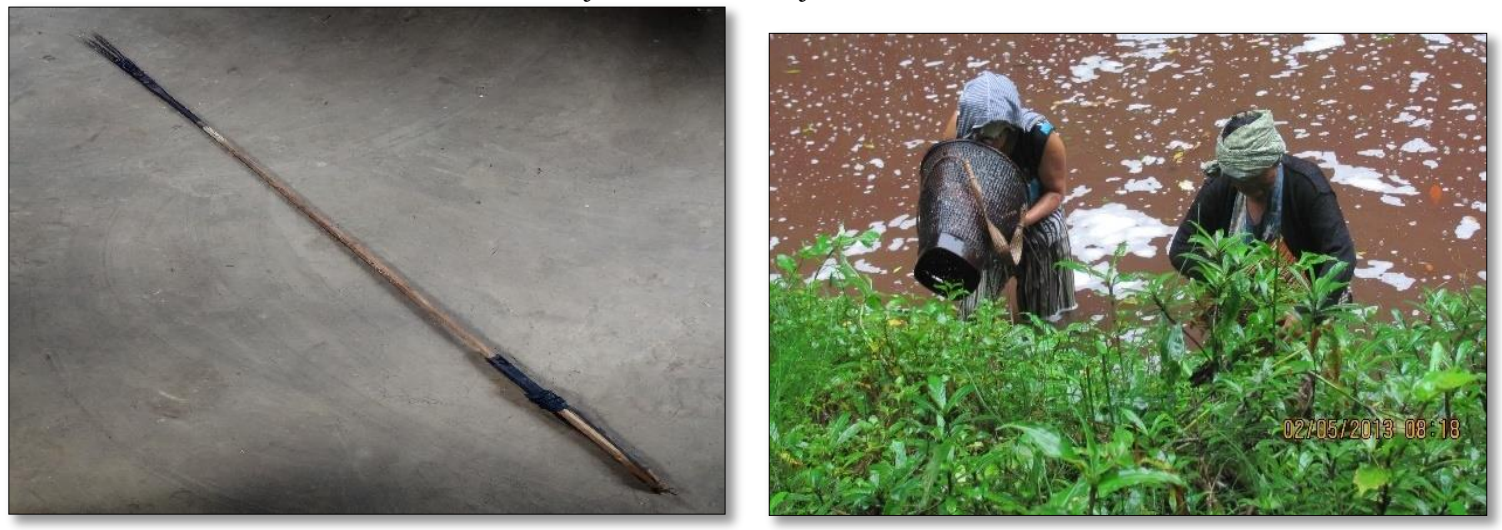

Fig.8: Ngakaapniithar

Fig. 9: Using Long and Bukaangidii for fishing

h. Thingna Iting: A particular tree called shorii or chiibarii (in Moyon language) found only at riverbanks are used in this fishing method. The tree branches with intact leaves are bounded into a bundle using bamboo strips; boulders are also tied to the bundle for it to sink underwater. The readied tree branches (bundles) are put into the river pools and left to soak overnight, or even for a week. On the desired day, the soaked bundles are slowly pulled towards the river bank. While pulling, cast nets and long and bukaangidii are employed to catch fishes trying to escape. When the bundles (of tree branches) are finally pulled out, they are cut open to see if there are any fish trapped inside. Large quantities of fishes as well as other aquatic beings like crabs and shrimps trapped inside the bundles are thus caught. Deep and stagnant river pools are the preferred sites for this fishing method. This fishing method is best used during the months of October and November.

i. Ngaaruw (fishbone): This method uses fishbone. The Moyons believe that the bones of certain fishes can attract fish. Fishing using fishbonewas traditionally popular in the months of October and November during the spawning season. The bones of Nganur (Anguilla bengalensis) were buried at selected sites along the river. Attracted by the smell of the bones, migratory fishes congregate around the spot to spawn. Fishermen took advantage of this congregation by quickly erecting barriers to not let the fishes escape. Cast nets, gill nets, long and bukaangidii were used for catching the fish. Conical traps would also be put up wherever the gaps are to trap any escaping fishes. This fishing method is no longer practiced.

\subsubsection{River Modification}

As the name suggests, this fishing category involves modification of the river channel in order to catch fish. The method includes,

a. Iva ithei (side-tracking) (Fig 10): This technique is popular during the dry season and used for catching all types of fish. It requires teamwork. Rivers with multiple channels are preferred. During the dry season when water levels are low, a group of fishermen would select a portion of the river. Using stones, boulders, leaves, and tree trunks, temporary dam-like barriers are erected across the river to block the water flow. Meanwhile, another channel is cut across the river bank to divert the water. Gradually water stops flowing below the dam/barrier. Taking advantage of the exposed bed downstream, fishes are easily caught. 
b. Phum ynthii (flushing) (Fig 11): This technique also requires teamwork. It is mostly practiced during the dry season when the water level is low. Intermittent streams with permanent deep pools are the preferred spots for flushing.

During the dry season, fishes tend to congregate in deeper pools of water. Blocking the flow of the pool by building a barrier/diversion, the water in the pool is then flushed out using baskets and hands. As the pool gets shallower, fishes are exposed for easy catching. Once the fishes are caught, the barriers are opened or diversion is closed to redirect the river back to its natural channel and the pool is flooded again.

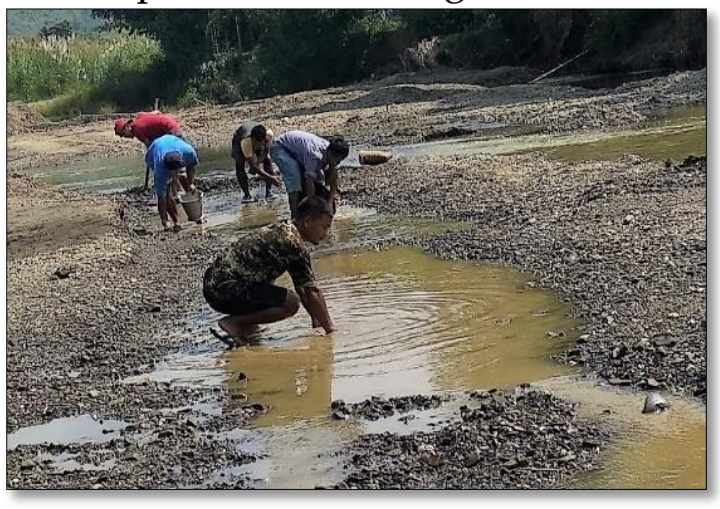

Fig.10: Iva ithei

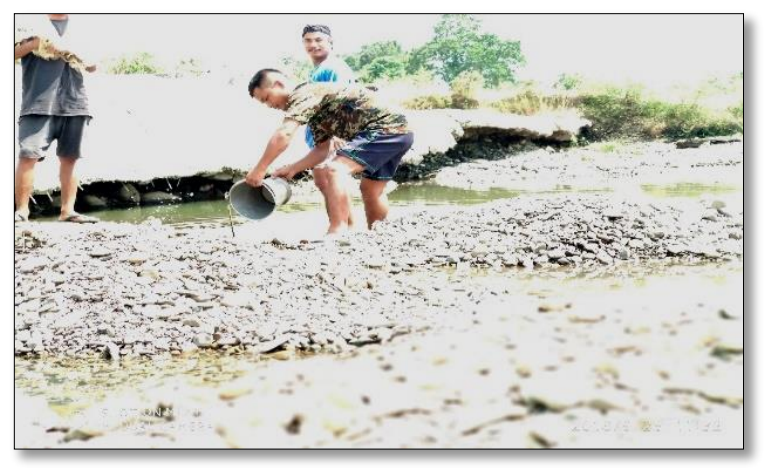

Fig.11:PhumYnthii

Using the above-mentioned various fishing techniques, the Moyon were able to fish the rivers for centuries. The fish they caught were sufficient to meet the occasional dietary needs of the people. The fish caught were preserved via drying or fermentation for future use (Wanglaret al 2018:28622). It can also be noted that the majority of these traditional fishing methods are effective only during the dry season when the water levels are low enough. On the other hand, people also make use of their knowledge of the time for fish spawning to fish at the right time. Although not prohibited, fishing is less common during the rainy season. The Moyons avoid fishing during the rainy season to allow the fish to grow. The other reasons could be high water levels or devotion to their primary occupation- agriculture.

In addition to the above indigenous fishing techniques used since time immemorial, the Moyons at present also employ modern fishing techniques or precisely introduced techniques. They are considered modern because they are more advanced than the traditional fishing techniques and are started to be used by people only within the last few decades. These modern techniques require less labor and are more convenient allowing maximum catch with less input.

\section{Discussions}

\subsection{Traditional fishing techniques and sustainability}

Traditional fishing techniques depending on the local knowledge of fish habitat and lifecycle. Initially, most fishing activities were carried out only during the dry season when the water level was low, which was also advantageous for fishing. Otherwise, some of the unspoken general rules among the community with regards to traditional fishing are as follows.

a. Usage of ichthyotoxic plants, especially Jaerii, for fishing was regulated. Since ichthyotoxins are potent and their effects could run many kilometers downstream, they have the potential to 
not only affect fishes beyond the collecting capacity (which was considered wasteful) but also kill juvenile fishes and other aquatic animals. Moreover, as some of the portions of rivers belong to particular clans, indiscriminate usage of ichthyotoxic plants would not only affect the intended river portion but also affect the river portion of other clans which could result in clan conflicts. Thus, the traditional regulation not only minimized indiscriminate misuse of such herbal fishing but also indirectly protected the fish population.

b. Community fishing (Chiituk) was an important traditional community herbal fishing event, but it was not an annual event. The usage of large quantities of ichthyotoxic plants could affect the aquatic life for many kilometers downstream and the fish population usually crashed following events of community fishing. Thus, community fishing was not an annual practice. There would be gaps of several years between successive chiituk events. The reason was to allow time for the fish population to recover.

c. Fishing during the rainy season was discouraged to allow young and juvenile fishes to grow. Thus, not fishing during the rainy season (growing period) ensured a good catch during the autumn season when adult fishes congregate to spawn.

d. Manual fishing methods using chem, isii, ngakapniithar, lungtuk, long, and bukaangidii were ideal only in low clear water. Moreover, they required patience, skill, and concentration apart from consuming energy and time. Thus, these methods were used for catching bigger fishes while small or juvenile fishes were usually skipped.

e. Fishing was and is traditionally discouraged when the fishes migrate upstream. The reason was to allow a maximum number of fishes to migrate upstream and spawn first. Only after the fishes spawned that they were fished. This unspoken rule indirectly safeguarded the spawning fishes by allowing them to spawn and thus ensured the sustainability of the fish population for the future.

f. Chapenor barrier guide) was usually not set up when the fishes migrated upstream. This was to allow the brooding fishes to migrate upstream for spawning. Only when the fishes migrated downstream after spawning that chapen was set up; thus, future sustainability of fish population was also ensured.

g. Fishers were encouraged to follow up their river modification activities like opening of barriers and re-diverting the river back to its original channel after the fishing was done. This was to ensure the natural flow of the river.

Despite the traditional fishing method inclining towards sustaining the fish population (and to protect future fishing), every now and then they were abused and misused for individual benefits. Ichthyotoxic plants were often over utilized by private fishing parties in order to catch maximum fish, but at the cost of fish population and aquatic ecology due to issuing ichthyotoxin pollution. It was also observed that some fishers secretly used a particular ichthyotoxic plant by the name Jaerii which was more potent and harmful to the aquatic ecosystem. Even though scoop baskets were considered harmless, their unregulated use especially during dry seasons resulted in water pollution. The Maha River currently suffers from overfishing and pollution due to widespread usage of scoop baskets resulting in the river remaining dirty and unpalatable most of the time. In addition, agricultural runoffs (containing 
fertilizers) also pollute the Maha River affecting the aquatic ecosystem by inducing an algal bloom in the river. The health of the people who consumed contaminated fish is also compromised due to chemicals in the river water and fish.

There were also observed cases and anecdotes of fishers erecting barriers (known as Chapen iting) when the fishes migrated upstream; thus affecting the brooding population. During the spawning season, there were always competitions among fishers to catch the fish. Thus, As soon as the fishes congregated to spawn, fishers would immediately start catching them. The reason behind this was insecurity and greed that the fishes might migrate upstream or elsewhere (into the fishing grounds of other clans), so, fishers would catch the fishes when they encountered the opportunity. Not allowing the spawning to take place greatly impacted the fish population; accordingly, the Chakpi River within the Moyon territory suffered from an unprecedented crash of fish population affecting the fishers' income.

Iva ithei and phum inthii involved modification of river channels, thus the channels need to be restored to their original state after fishing. However, fishers would not bother to open the barriers. This affected the natural flow of the river during floods and spates resulting in soil erosion of river banks. Constant soil erosion of the banks of Maha River destroyed many kitchen gardens at the riverbanks which also affected the livelihood of cultivators.

Thus it can be stated that even though traditional fishing methods are theoretically sustainable, they could become unsustainable and destructive if not employed wisely. The desire to catch more fish has pushed the fishers to adopt every means and method resulting in the adoption of more advanced fishing methods that are often very effective but disastrous in the long run.

\subsection{Modern fishing methods and effects}

The fishing issue is even more aggravated as modern fishing methods began to be used. Some of the modern fishing gears used are, scoop nets, gill nets, gelatine and explosives, dynamo (for electrocution), lime, and bleaching powder (Wanglar and Arunkumar 2017). These modern gears are advantageous over indigenous methods because they can be used at any time of the year regardless of water level and season. Thus, they are indiscriminately used without little regulation.

A brief description of selected modern fishing methods is as follows.

i. Gelatine and explosives: Gelatine sticks and other explosive materials are lighted and hurled into deep river pools. The issuing blast kills the fishes which are then collected using scoop nets. This method was very popular in the Lokchao River resulting in irreparable damage to the fish population. Blast fishing became popular in the early 2000s. This method is currently banned.

ii. Lime and bleaching powder: Lime and bleaching powder are poured into the river. The issuing chemical reaction kills aquatic animals (fishes, shrimps, and crabs) downstream. This method is so destructive to the river ecosystem that it is also currently banned.

iii. Dynamo: Fishing using dynamo became popular in the 2000s. The gear consists of three parts: a portable lead-acid battery, a dynamo (locally made) and flat metal mesh connected via a wire to the dynamo. This method employs electric shock to shock, stun or kill the fish. Since it is 
portable and easy to operate, the dynamo is very popular among amateur fishers. Considering the negative impacts, most villages banned dynamo.

iv. Electrofishing (using high voltage electricity): This method is currently banned. In order to fish, a wire is connected to transmission wires (literally stealing electricity). The wire is then dipped into deep river pools to kill fish. Although not very common, this method was secretly used in the Maha River. Considering the dangers of high voltage electricity and the illegality of stealing electricity, villages banned this method. Anyone caught fishing using these method is punished by the community.

The usage of modern fishing methods left a drastic impact on the fish populations. Since modern fishing gears are easily available in the market, they are used throughout the year. Although these modern fishing methods allowed the fishers to catch more fish, the benefits were short-term while the impacts were long-term. Small fishes, juveniles, and fishes in deep pools which were untouched by traditional fishing methods are extensively targeted by dynamo, explosives, and bleaching powders. Whereas traditional fishing gave time for the fishes to grow or spawn, modern fishing gears with their easy use do not discriminate between big and small fishes. Due to extensive usage of the dynamo, explosives, and bleaching powders during the off-season, the fish population in the Chakpi River crashed beyond recovery. In recent years, the quantity of fishes caught during spawning seasons has drastically decreased; many blamed indiscriminate usage of modern fishing methods for the decline.

Another effect of modern fishing is the increase in aquatic pollution. Dynamos are handy to stun/kill fish hiding inside holes and deep pools. Many of the fishes after electrocution were not recovered due to difficulty in recovering. They thus rot inside the holes and pools polluting the water and affecting the ecosystem. Using lime and bleaching powder resulted in chemical pollution killing large quantities of aquatic species; the unrecovered fishes rot in the river causing stench and water pollution. The Maha River currently suffers from the effects of extensive usage of dynamo (electrofishing) and the Chakpi and Lokchao Rivers suffer from indiscriminate usage of explosives.

Interestingly, there is a cycle of decline in fish population and pushing of modern methods. As the fish population declined due to extensive usage of modern fishing methods, fishers pushed themselves to venture even further to catch the remaining fish. As the remaining fishes were caught, there were not enough fishes to breed for recovery of population resulting in further decline of the fish population. The further decline of the fish population, the further fishers use scoop nets, explosives, and dynamos: the cycle goes on and on. The irony is that many of the fishers are not aware that their fishing methods are the culprit behind the decline in the fish population. Whereas fishers lamented the decline in the fish catch, they were not ready to give up modern fishing techniques. Rather, they cited (during personal discussions) the decline in fish population and catch as the reason behind their usage of these modern destructive fishing techniques. 


\section{Conclusion}

It is usually said that indigenous people are the protectors of the environment, but, unfortunately, human greed can force the Moyon folks to venture towards unsustainable fishing. Although measures are being taken up by the community to protect the remaining fish population with the aim to pave way for sustainability, local fishers hardly pay attention to such regulations. On the other hand, at times, fishers from other tribes would venture into the Moyon waters creating social tensions and conflicts.

The remoteness of the region means that destructive fishing modus goes unnoticed. At the same time, poverty and struggle to survive also push the fishers to venture further with their newly found modern fishing techniques to catch more fish which in turn would feed their stomach. Thus, poverty in the region and usage of destructive fishing techniques are also co-related. To address the issue of poverty and lack of alternative livelihood opportunities, education and awareness are a must.

However, it is also unfortunate that the villages on the Basins of Chakpi and Lokchao Rivers lack basic educational and developmental facilities. There is hardly any functioning school in all the villages. Being remote, teachers (mostly from urban or other villages) refused to come to the villages while continuing to withdraw salary in absentia: this is in fact one of the rampant educational problems in the entire Chandel District. The villages also lack basic development projects, bad connectivity and there are hardly any awareness events on the importance of the environment and sustainability. On the other hand, the market demand for hill fishes also increases every year. With the hill fishes fetching premium prices, fishers are always tempted to adopt destructive fishing techniques for maximum catch and thus maximize their profit, but at the cost of the environment and their future. In addition, there are potentials of discovering new fish species from Chakpi, Lokchao, and Maha rivers and their tributaries, as demonstrated by Wanglar and Arunkumar (2016, 2017, 2018, 2019, \& 2020) in many of their studies. Thus, there is also the possibility that indiscriminate fishing might result in the disappearance of fish before being scientifically discovered and studied.

Sensing the decline in fish population and the importance of sustainable fishing, Moyon villages undertook various measures. Dynamo, explosives, and bleaching powder are currently banned by the community. Anyone caught using them is punished with fines. The usage of scoop baskets is also discouraged during the dry season in order to control river pollution and protect small fish.

Fishing, including the erection of barriers, is also regulated at the Chakpi River during dry seasons. This regulation is for the recovery of the fish population as well as to allow the fish to grow. In addition, outsiders (non-Moyon) are strictly prohibited to fish in the portions of the river belonging to the Moyon tribe. Since every tribe in the region has its own territory and resources, to fish in the waters of other tribes is regarded as stealing of resources which has the potential to incite inter-village and inter-tribe conflicts. Moreover, the purpose of banning other tribes is to ensure the protection of Moyon resources in light of unregulated resource exploitation in the region. For example, some neighboring villages of Kapaam village (at the Maha river basin) started fishing the river portions belonging to Kapaam village after they 
finished fishing their streams. The people of Kapaam were not happy with such activities because the other tribes not only intrude into their territory but their fishing activities also resulted in serious water pollution rendering the Maha River unfit for consumption. In the month of March 2020 when the Covid-19 lockdown was enforced, some fishers belonging to other tribes secretly fished Maha River much to the dismay of Kapaam village because the fishers not only fished in their water but they also broke all the Covid-19 protocols endangering other villages.

In recent years, picnics and other recreational activities are also regulated at Chakpi River. It was observed that picnic-goers and other recreational parties would dump their waste (plastics, bottles, and leftover food) into the river resulting in water and riverbank pollution. Moreover, in the guise of picnics, people secretly used dynamo for fishing. Although this regulation was hardly paid attention to by the people, it showed that the community is seriously considering the need for environmental conservation. Over and above, there have also been some initiatives from the side of the environment-conscious individuals to educate and create awareness among the younger generations on the importance of environmental sustainability. These educational and awareness initiatives were partly fruitful considering the younger generations becoming more vocal on environmental topics;signboards on the protection of birds and animals were also put up everywhere to remind the people of the need for environmental conservation.

By protecting the fishes and ensuring the availability of fishes in the future, the Moyons also ensure the survival of their local/ indigenous fishing cultures and ecology. Otherwise, the Moyon community will exhaust itself of its resources and heritage and by the time realization hits them, it might be too late to take any action. Hence, responsible fishing along with environmental awareness is to be encouraged and promoted. By protecting the fishes, the community will also indirectly preserve the knowledge of indigenous fishing methods as well as the art of making indigenous fishing gears like long and bukaangidii (scoop baskets), iruw (conical traps), ngakaapniithar, etc. As of now, the knowledge of making indigenous fishing gears is being forgotten very fast as modern fishing gears are available at cheaper rates in the market. At the same time, it is also essential for people to acknowledge the importance of resource sustainability.

\section{Limitations and Directions for Future Research}

The study is limited only to the traditional fishing methods used by the Moyon tribe. Similar studies on traditional fishing methods by other tribes and communities can also be executed at a larger scale in the future. The study does not cover the socio-economic and development experiences of the community. As one of the minor tribes inhabiting in a backward region, there is also need for research related to the development issues and dilemmas in the region.

Authors' Contributions: Wanglar Alphonsa Moyon and Elija Chara conceived the idea for the article. Moyon collected the data on indigenous fishing methods used in Chakpi and Lokchao Rivers and ichthyotoxic plants used in herbal fishing; Chara collected the data on fishing 
(C)Moyon \& Chara

methods used in Maha River, modern fishing methods and socio-economic conditions of Moyon villages. Wanglar compiled and analyzed the data; Chara wrote the article.

\section{Conflict of Interest:The authors declare no conflict of interest.}

\section{REFERENCES}

Arunkumar, L.,\&Moyon, W.A. (2016) Schozothorax chivae. A new schizothoracid fish from Chindwin basin, Manipur, India (Teleostei: Cyprinidae).International Journal of Fauna and Biological Studies, 3 (2),65-70.

Arunkumar, L.,\&Moyon, W.A. (2017) Glyptothorax chavomensis sp. Nov. (Teleostei: Sisoridae) with its congeners from Manipur, North-Eastern India. International Journal of Zoology Studies, 2 (5),242-252.

Arunkumar, L.,\&Moyon, W.A. (2019). Garra ngatangkha is a new labeonin species of Lissorhynchus complex (Teleostei: Cyprinidae) from Manipur, North-Eastern India.International Journal of Fisheries and Aquatic Studies, 7(3), 285-290.

Arunkumar, L.,\&Moyon, W.A. (2020). Paracanthocobitis tumitensis, a new species of zipper loach from Manipur, north-eastern India (Cypriniformes: Nemacheilidae).Species, 20, 101-109.

Chara, E. (2018). Identity in the Oral History of Bujuur Naga.Current Research Journal of Social Sciences and Humanities, 1(1), 37-44.

Chara, E. (2021). Memory and Identity: Narrations on Aemo-Bujuur.Asian Ethnicity, 22(3), 410-427.

Moyon, W.A.,\&Arunkumar, L. (2017). Ichthyotoxic plants of Manipur.International Journal of Fauna and Biological Studies, 4(4), 29-36.

Moyon, W.A. (2018). Ichthyofauna of Chiva River, Chandel District, Manipur (Ph.D. Thesis). Himalayan University: Itanagar.

Moyon, W.A.,\&Arunkumar, L. (2018). Garra moyonkhulleni, a new labeonine species (Cyprinidae: Labeoninae) from Manipur, north-eastern India.International Journal of Fisheries and Aquatic Studies, 6(5), 107-115.

Moyon, W.A.,\&Arunkumar, L. (2020) Garra chivaensis, a new lebeonin species (Cyprinidae: Labeoninae) from Manipur, North-Eastern India.Species, 21(67), 32-42.

Wanglar, W.A., Arunkumar, L., \&Tarao, S.M. (2018) Fish Preservation Techniques practiced by the Moyon tribe, Chandel district, Manipur.International Journal of Recent Scientific Research, 9(8), 28622-28626. 